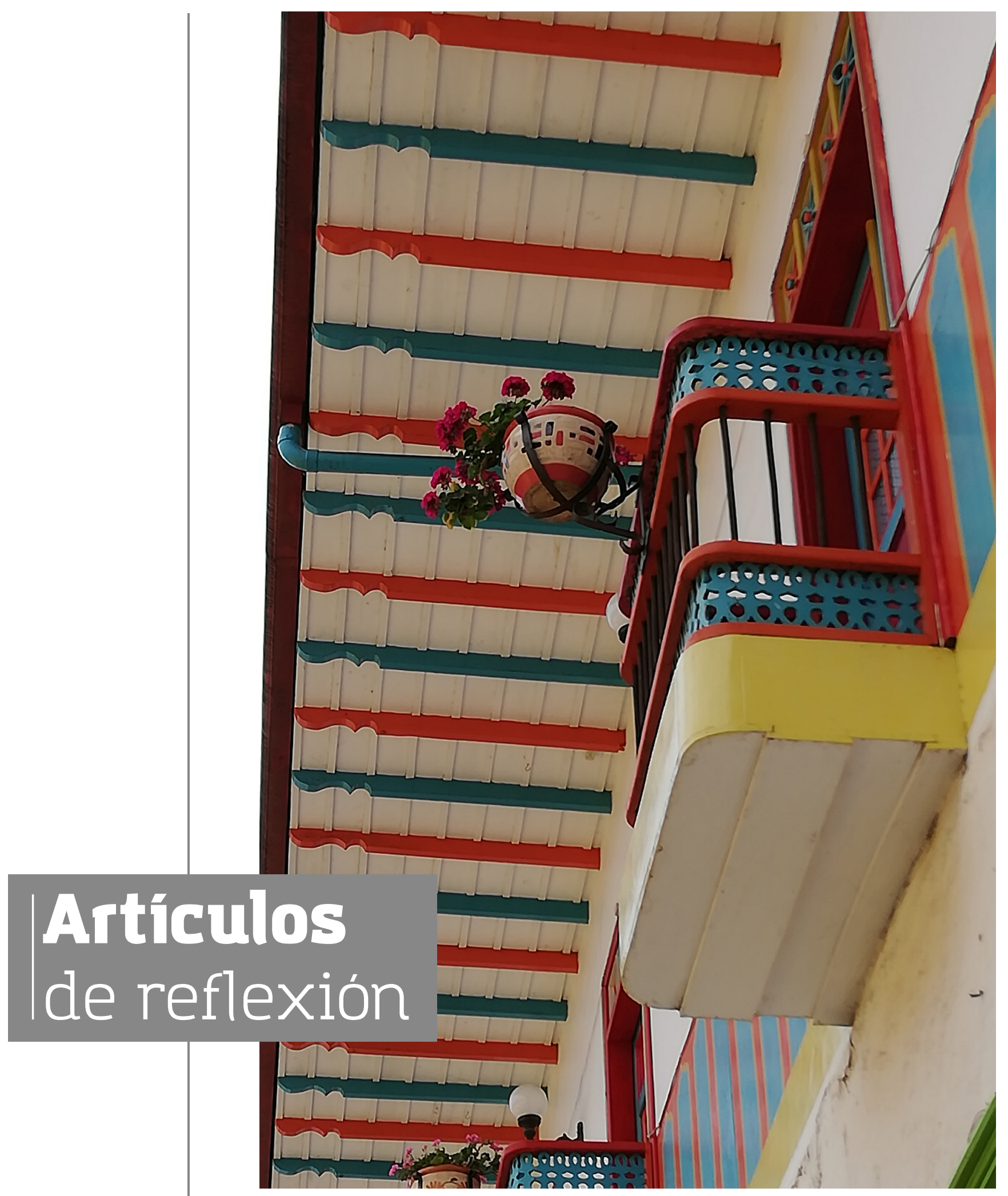




\section{Sobre voces y poder: hacia una semiótica del silencio}

\section{On voices and power: towards a semiotic silence}

https://doi.org/10.18566/comunica.n44.a05

Recibido: 18 de diciembre de 2020

Aceptado: 25 de marzo de 2021

\section{Resumen}

En este artículo proponemos pensar el acontecimiento del silencio desde dos puntos de vista: como signo-síntoma y como elemento de poder social. Para avanzar en esto diferenciamos, por un lado, los actos de callar y silenciar y, dentro de este, el de ser silencioso o ser silenciado, apoyados en las propuestas de Jacques Lacan y Roland Barthes. Posteriormente, fijamos la reflexión en dos casos concretos que involucran sectores de letrados: el del cada vez mayor silencio que aqueja a los docentes en el siglo XXI y el de los pactos de silencio en el orbe político del país en el siglo XX. Tal esfuerzo permite concluir que la figura del letrado, docente o autor de obras culturales comunica desde lo ausente con la intención de denunciar un malestar estructural, ora desde sus omisiones, ora desde sus alusiones académicas.

\section{Abstract}

In this article it is proposed to think about the event of silence from two points of view: as a sign-symptom and as an element of social power. In order to advance on this, a difference had to be made in the one hand, the acts of silence and to silence and, within this, being silent or being silenced, supported by the proposals made by Jacques Lacan and Roland Barthes. Then, the reflection is focused on two specific cases which involve sectors of intellectuals: the increasing silence afflicting teachers in the 21st century, and the one of the pacts of silence in the country's political sphere during the 20th century. This effort allows us to conclude that the figure of the intellectual, teacher or author of cultural books, communicates from the absent with the intention of denouncing a structural discomfort, or from their omissions, or from their academic allusions.

\section{7}

Comunicación

número 44

Enero- junio

2021 | pp.77-92

\section{Éder García Dussán}

Profesor e investigador

de la Facultad de Ciencias

y Educación (FCE) de la

Universidad Distrital,

Francisco José de Caldas.

https: / / orcid.org/0000-

0002-6635-2725

eagarciad@udistrital.edu.co

\section{Palabras clave}

Voz, silencio, acallamiento, malestar docente, pacto, víctima.

\section{Keywords}

Voice, silence, shutdown, teacher discomfort, pact, victim. 


\section{Introducción}

Afirma el cuarto evangelista que "en el principio el verbo (logos) era, y el Verbo era junto a Dios, y el Verbo era Dios. Él era, en el principio, junto a Dios" (Juan, 1, 1-3). Como se nota, se apuesta aquí por una primacía ontológica de la palabra que, suponemos, dice todo y crea todo (Génesis, 1, 3). No obstante, dos comentarios a propósito de esta idea pueden servir de prefacio a la propuesta: primero, antes de la palabra debió existir el silencio, porque todo enunciado nace de un tiempo en blanco, de un silencio cósmico, definido por los gnósticos como el principio metafísico divino (Fierro, 1992); y, segundo, consideramos que el silencio, visto como gestión humana, y ya a ras de tierra, "dice algo a alguien", y se fractura, como la palabra en lo social, en sentidos e interpretaciones.

En este contexto, llama la atención la cada vez más frecuente pérdida de voz de varios actores sociales, así como también su articulación o su falta de estímulo para iniciar un diálogo; es decir, el acto de despachar un mensaje al otro o que, de lograrse, se conviertan en mensajes inacabados o tímidamente enunciados, con mínimos grados de perlocución, tal y como viene sucediendo en los contextos educativos y políticos del país (Abril, 2008). Es que no puede pasar desapercibido el ruido que genera el silencio, pues, por ejemplo, ser profesor o intelectual cultural es un quehacer que se funda justamente en el uso y efectos de la voz, mientras que ser ciudadano implica hacer uso de su voz en lo público para ejercer ciudadanía, como ya bien lo enseñaba Kant hace más de dos siglos.

Ahora bien, para avanzar en el entendimiento de este tipo de sucesos proponemos especular sobre la función de la voz y su opuesto, el silencio, desde algunos aportes que ofrece, por un lado, la semiología general y, por otro, la semiótica médica (el psicoanálisis), lo que nos permitirá especular la posible gestación de una microsemiótica doble que trate sobre la dicotomía ser silencioso (en la escuela) versus ser silenciado (en la sociedad). Se trata, pues, de pensar los procesos comunicativos en el contrato escolar y en la comunidad imaginada que es Colombia como entrecruzamientos "performáticos" de muchas voces; pero, también, de sus ausencias, de sus quebrantos y de las reacciones ante el poder político, que usan el silencio como mecanismo de encubrimiento y olvido.

\section{El silencio y la semiótica}

Pues bien, según Sigmund Freud, el ser humano habla para equilibrar sus tensiones psíquicas, que son reguladas por el principio del placer; esa es la primera función del grito, del llanto o del sonido gutural en los críos (Freud, 
1982). Aquello que produce el crío obliga al Otro a ser interpretado, de suerte que el grito se convierte en signo lingüístico, y en semiosis, lo que certifica su existencia (ex sistere), posible gracias a, primero, un "silencio-objeto", aquel que se instala antes del grito y que señala la vida, y, luego, a un "silencio-sujeto", el que legaliza en un lazo a alguien después del nacimiento (Lemoine, 1982). Así las cosas, la voz es el medio para que alguien cree vínculos sociales, al tiempo que es instrumento de representación frente a los otros. Pero cabría la cuestión: ¿y el silencio también tiene funciones comunicativas?

Más de 70 años después de haber hablado Freud, en una de las clases del seminario La Lógica del Fantasma, en 1967, el psicoanalista francés Jacques Lacan retoma la distinción entre tacere y silere. Tacere es aquel quien calla, y lo hace cumpliendo el derecho de ser "tácito"; en suma, quien calla tiene un saber y las palabras para comunicarlo, pero no lo quiere decir; mientras silere significa invocar el vacío de significantes nunca ocurridos y, por tanto, la existencia de un saber que no se sabe y que, por esto mismo, se somete a un puro por-venir, al "efecto de una palabra en espera" (Thomas, 1999, p. 81). Una década después, el semiólogo francés Roland Barthes indicaba tal diferencia de esta forma: “... En la lengua clásica es lo mismo: callarse, permanecer en silencio. Pero antes, matiz interesante: tacere $=$ silencio verbal $\neq$ Silere = tranquilidad, ausencia de movimiento y ruido" (2004, p. 67).

Así las cosas, no es lo mismo estar callado o ser callado, ni tampoco estar en silencio o ser silencioso, pues quien calla o se silencia genera un sentido, siempre y cuando "se lo[s] acompañe de una palabra explicativa que use su sentido (...) sentido que, por otra parte, es polisémico" (Barthes, 2004, p. 73).

No obstante, esa explicación es una tarea que Barthes propone, mas no desarrolla del todo cuando lo ambiciona hace más de 40 años. Una forma de hacerlo en la actualidad consiste en enlistar y analizar especificidades entre tacere y silere como dispositivo base para avanzar en la reflexión, que se reduce a un juego de transitividad e intransitividad gramaticales, puesto que, por un lado, tacere o aphasia equivale a "estar o permanecer callado"; pero también "callarse" (reprimir el acto de habla) o "ser callado" (por alguien); mientras que silere es estar en silencio o guardar silencio, lo que involucra el ser silencioso, silenciario o silente (de poca habla, discreto), y también es aquello que tiene que ver con imponer silencio o reducir a alguien al silencio.

Ahora, de esta potencial forma de combinar opciones a propósito de los dos verbos en cuestión, y que podríamos llamar la sintaxis del silencio, propondremos cinco casos, anudando su carga semántica con algunas 
aproximaciones que pueden provenir del uso de elementos pragmáticos. Estos casos son:

1. quien permanece callado voluntariamente;

2. quien es callado por efectos de la represión;

3. quien se silencia por disfunción orgánica;

4. quien se silencia, espontáneamente, acaso en contra de su voluntad consciente;

5. quien es silenciado por efecto de un pacto político impuesto.

En lo que sigue desarrollaremos con mayor agilidad los primeros tres casos enlistados para, después, hacer un escrutinio más sesudo en los últimos dos, dado que es el interés del artículo porque permite destilar o desgajar premisas para una posible semiótica, general y diacrónica, del silencio, fundamentando aquí sus premisas epistémicas, tal y como sucede con la existencia de semióticas para otros códigos usados en la comunicación humana.

El primer caso es el de "quien permanece callado voluntariamente". Se trata de aquel sujeto que no dice las palabras porque cree que no es prudente decirlas; esto es, se abstiene de comunicarlas, para lo cual toma refugio en expresiones como "no me obligues a hablar", "podría decírtelo, pero prefiero no decirte la verdad" o, en términos de Wittgenstein, "de lo que no se puede hablar, es mejor callar" (1994, p. 129). Esto es, que, para evitar decir una verdad destructiva, el sujeto "se muerde la lengua". Esta actitud tiene hondas raíces cristianas que sugieren no hablar abusivamente, ${ }^{1}$ lo cual se asocia a una moral que anuda el valor de la modestia. Ser modesto consistía en evitar cualquier exceso. Para los primeros cristianos, "modestia" era sinónimo de temperantia, que se trataba para Cicerón (2006) de ejecutar cualquier acción y pronunciar cualquier palabra con orden y medida.

De esta suerte, callarse a tiempo o no hablar mucho está asociado a una tabla de valores morales alimentados por siglos en comunidades religiosas, actitud que ha sido resignificada en las reflexiones pragmáticas modernas con el mote de principio de cooperación y sus máximas, desarrollado por Paul Grice (2005); especialmente, la máxima de cantidad que reza que la contribución de un hablante no debe ser más informativa de lo necesario, puesto que hablar o hablar de más puede empotrar a un sujeto en problemas.

El segundo caso es el de "quien es callado por efectos de la represión". Efectivamente, existen los casos donde no se trata de callar, sino de ser callado. Para darle forma a este caso podemos recordar un episodio sucedido al mismo Sigmund Freud, quien, con 26 años y ejerciendo la medicina, escribe una carta a su novia Martha Bernays. Ofuscado por los celos y tras un movimiento insospechado de su mano, gotean de su pluma
1 “... No te des prisa con tu boca, ni tu corazón se apresure a proferir palabra delante de Dios (...) porque de la mucha ocupación viene el sueño, y de la multitud de las palabras la voz del necio" (Eclesiastés, 5: 2-3). 
pizcas de tinta que dejan algunas manchas en el papel. Entonces, aprovecha el accidente para rodear con un círculo de tinta las manchas y, dentro de él, escribir en letra más pequeña "... Aquí la pluma se nos cayó de la mano y escribió este signo secreto. Te presento mis excusas y te ruego que calles, que no efectúes su interpretación" (Freud, citado por Rodríguez, 2011, p. 8).

Callar al otro, entonces, implica un acto de violencia que instala un secreto a voces. En este caso, lo cierto radica en que hay una contigüidad de pensamiento (metonimia) que va de lo social a lo sexual. Es que no es dificil captar la vecindad entre el goteo de una pluma sobre el cuerpo de la escritura y la escena del clímax de un comercio carnal entre un hombre sobre el cuerpo de una mujer en la postura del misionero.

Así, al callar a alguien, lo que se intenta es detener la posibilidad de interpretar el mensaje para obtener una verdad que, en todo caso, forma parte de un tema tabú. Entonces, una solución es cohibir una lectura, lo que de suyo no evita que "algo caiga" y deje al descubierto una intención.

Un tercer caso es "quien se silencia por disfunción orgánica”. Por ejemplo, a quien se le han estropeado los pliegues vocales, lo cual ya es interpretable más allá de su afectación física si se trae a escena la hipótesis de la relación psicosomática de las enfermedades. Son vox populi los casos de profesores que se han beneficiado de la Ley 860 de 2003, la ley de pensión de invalidez por enfermedad profesional en Colombia, debido a problemas de la voz; más exactamente, movimiento paradójico de las cuerdas vocales, diagnosticada a partir de sintomas como la sensación de que falta el aire (disnea), inestabilidad fonatoria y opresión en la garganta, descrita como un estrangulamiento; una de sus causas más frecuentes es el estrés laboral (Guzmán et al., 2009).

Para la praxis psicoanalítica, la enfermedad no es más que la punta de un iceberg, un problema que no está en el aparato fonador del sujeto, sino en otro lado, pero manifestado en la configuración biológica. Puede ser leída aquella como una simbolización, proceso con el cual se tropezó el joven Freud (1976) y que se manifiesta como una identidad entre símbolo y síntoma, donde prevalece el significante y certifica la semejanza entre un "a/e/fecto sintomático" (lo psíquico) y la "realidad significada" (lo somático). Este mecanismo puede explicar la afonía o cualquier otro malestar que recaiga sobre la voz de un sujeto; por ejemplo, cuando este dice ante los destinatarios "así no hablo (ja)más, no me comunico más". "Así", es decir, en ciertas condiciones, en las condiciones laborales.

Ahora, otros casos relievan sujetos que "se silencian espontáneamente", que actúan bajo un hecho involuntario o inconsciente, lo cual también 
es interpretable porque, sabemos desde Lacan, que "lo inconsciente está estructurado como un lenguaje" (1987, p. 21). Aquí el silencio aparece como un lugar del cual aún no surge nada, "el lugar expectante del parto de una voz que, con suerte, devendrá sonora” (Ramírez, 1992, p. 23). Este es el cuarto caso de los enlistados arriba y corresponde a aquellos que se silencian. En efecto, es quien parece que deseara mantener vírgenes las palabras o, si nacen, no comprometerse responsablemente frente a lo que pueda advenir o porvenir como discurso.

Esto sucede, por ejemplo, en la alocución simulada; es decir, cuando el sujeto finge que no dijo algo, pero, en todo caso, lo dijo. Efectivamente, son palabras que salen de otro lado (de la esfera inconsciente) y florecen por la boca del mismo sujeto (consciente). Entonces, este dice "se me escapó" o "se me chispoteó", no sin sentir angustia o pena. La palabra usada por Freud para estos casos es Witz, algo así como "chispa verbal", una "metida de pata" (Freud, 1979a, p. 178); es "ese no sé qué que no se deja pensar desde la norma" (Lacan, 2001, p. 34), y cuya apología se basa en el adagio "el pez muere por la boca".

Por tanto, el silencio comunica, aun sin significantes o con significantes marcados por la lógica del Witz, pues están dirigidos a otro y porque, desde la experiencia, se sabe que los silencios tácitos, los silencios inconscientes o las metidas de pata dicen sin querer o quieren decir algo de más y que, al final, resultan ser para el mismo enunciador una inquietante extrañeza, lo cual relieva un caso típico de lo ominoso (Das Unheimliche), esto es, algo que deja al sujeto con una sensación de angustia profunda provocada por el hecho de vivir como no familiar algo que debería ser reconocible (Freud, 1979b). La presencia de lo ominoso le permite a Lacan afirmar que “... el camino del sentido lo abre el sinsentido que en ese instante nos deja estupefactos, pasmados" (2001, p. 89).

Ya ubicados en este tipo de silencio, sostenemos la hipótesis de que esta es una herramienta del discurso inconsciente que se aparece como indiciosíntoma, una matriz que produce efectos de sentido que son comprensibles, dependiendo del conjunto de circunstancias contextuales que rodean ese discurso donde el silencio se acopla. Así que el silere-signum es un sileresymptoma "... de manera que el silencio no es no-decir, sino silenciar aquello que no se quiere, no se debe o no se puede decir" (Castilla del Pino, 1992, p. 80). En este orden de ideas, el silere en/de ciertos hablantes no velaría datos, sino lo contrario, de-velaría un escenario, aunque conflictivo.

El silencio en este escenario se torna, entonces, en el objeto de estudio de la semiótica de las ausencias (de significantes), cuyo objeto de estudio sería el crecimiento de los blancos comunicativos; esto es, de lo que no 
está, entendiendo que lo ausente es lo que provoca y convoca la presencia de una interpretación y que se tornaría un campo de investigación, el de un habla del silencio (y no una tengua del sitencio). En ese sentido, "hablar" con silencios (y no "lengüetearlos") estaría poniendo a prueba el refrán "a buen entendedor, pocas palabras", donde ya se instala la meta misma de la disciplina, a saber: aprender a leer al otro (y lo otro) desde los pocos o nulos significantes del sujeto, de suerte que “... con ello lo blanco viene a ser no sólo límite del discurso, sino también el elemento suyo, interno y constituyente" (Fierro, 1992, p. 49).

\section{Semiótica de las ausencias. Sobre el silencio docente}

Ahora bien, si llevamos todo lo anterior al mutismo del docente en sus escenarios profesionales, sea callando o sea silenciándose, ponemosa prueba la naciente microsemiótica de las ausencias. Esto es, si afirmamos la tesis de que el silencio es un objeto-de-estudio estructurado semióticamente, la pregunta es "... ¿qué quiere decir alguien al no decir nada en un caso concreto?" (Ramírez, 1992, p. 20).

Pues bien, si retomamos lo planteado atrás, aquello de que el silencio-signo es un silencio-sintoma, es importante recordar que todo síntoma es el efecto que acompaña un conflicto disfrazado que se simboliza, se marca por la primacía del significante sobre el significado. Si es así, en el caso de los docentes silentes, ¿qué conflicto estaría comunicándose?² Una respuesta pondría a la luz los conflictos de su propia profesión. Y esto, por lo menos, dando relieve a cuatro aspectos:

- El silencio docente como síntoma corp-oral. Como pocos sucesos motivan o atrapan a los estudiantes, el mensaje del profesor termina siendo inocuo; entonces, su voz se proyecta como un acto sin perlocución. Ahora, frente a la pérdida del poder de las palabras del docente, el silencio sería una forma de fundar la repetición de que sea escuchado, así sea marcando un síntoma corp-oral. Así las cosas, al estar ausente la voz, esto llama, atrae la atención; de la misma forma que frente al cuerpo femenino perdido, un tatuaje marca la ruta que lleva al goce, aquel que reivindica el cuerpo del placer, cada vez más eclipsado.

- El silencio, síntoma a-social. La protesta, la queja, la forma de desenmascarar lo oculto para las masas termina siendo acusada como propia de "mamertos", "criticones" o, incluso, "comunistas". Y, en este caso, el compromiso de denuncia se hace un búmeran que atenta contra la imagen de un intelectual, lo que, a la postre, lo excluye y, con él, su voz.
2 Un conflicto que, además, y de manera literal, lo hace vivir un regreso a su vida infantil, pues "infante" es quien no habla (in-fans). 
- El silencio docente como síntoma re(a)gresivo y topo-fónico. Si el mundo laboral no satisface en su realización personal a un docente y sí le genera intranquilidad (no conocemos profesor que no se queje de su profesión), al silenciarse se inhibe, evitando así un conflicto con el entorno. Esta inhibición, según Freud (1991a), es frecuente en el trabajo profesional. Así las cosas, el silencio es una respuesta que le permite al docente huir del malestar del mundo laboral para volver al mundo paradisíaco; una forma dialéctica de aproximarse a algún locum imaginatum, pero al precio de anudarse a la angustia (Freud, 1979b).

- El silencio docente como síntoma de una tensión de deseos. Como sabemos, es posible sostener una relación de transferencia instaurada en la dupla docente/estudiante. Al respecto, Freud afirma que las transferencias son reediciones del conflicto que regularmente actualiza un momento de la vida infantil y que pone en juego la relación médicopaciente (Freud, 1979c, pp. 93-105), pero “... la transferencia domina incluso de manera general las relaciones de un individuo con su entorno humano" (Melman, 1984, p. 34); por tanto, esta no es solo un accidente de la terapia, sino que es, en sí misma, un hecho estructural del sujeto. Así las cosas, un educador se puede convertir en una figura a la que son dirigidas todas las proyecciones afectivas por parte del alumno, porque este decreta a aquel como un objeto de una transferencia, y lo que se transfiere es el conjunto de las experiencias vividas previamente, ya que el deseo se aferra a formas particulares, y es el profesor quien las desaloja de su sentido simbólicamente establecido y las transfiere a esas formas que le interesan.

De esta forma, todo estudiante transfiere o proyecta sentido y poder al "educador", el cual termina englobando algo que pertenece al estudiante, quien, movido por su propio deseo, lo pone como soporte de su proceso formativo. No obstante, ese deseo, y su sentido particular, escapa al profesor. Tal vez este podrá tener algunos destellos del deseo de su discente, pero el trabajo de desenmascaramiento total no será posible. En cuanto al estudiante, pues ni quiere ni sabe el contenido de su deseo, ya que él solo apuesta a que el profesor soporte el lugar en que es puesto por su deseo.

Así las cosas, la interacción profesor/estudiante se lleva a cabo desde una tensión de deseos, porque el profesor debe aceptar el modelo que el estudiante le confiere, lo cual supone el decaimiento de su propio ser con el fin de permitir que el estudiante siga el rumbo hacia su madurez intelectual y moral, tal y como en un momento lo hicieron sus padres. Pero tal exigencia puesta al educador resulta improbable dentro de una cuantiosa masa de educandos a cargo y su mero asomo libera una agresión y una transgresión que tiene que menguar gracias a los límites de la realidad circundante para educar. Esta tensión se traduce en una elección: o satisface sus propias 
pulsiones o las sublima para dirigirse a su tarea conscientemente. En este panorama cabe la pregunta por si el maestro debe estimular y tolerar el juego bajo la imposición de "soporte" que le atribuye el estudiante o, finalmente, reacciona liberando la satisfacción pulsional.

No obstante, lo que suele verse en las aulas es que se efectúa una imposición de los valores e ideales del profesor, con lo cual se sobrepasa aquel deseo que mueve a todo estudiante a ubicarlo como sostén de sus deseos. Al ceder a esta tentación, el docente, protegido por el puesto de poder que ocupa, impone su deseo, haciendo que se eclipse el poder deseante del estudiante, lo cual se refleja en el viejo código inconsciente y negativo del maestro, el de Prügler (tundidor); es decir, el de alguien físicamente fuerte que golpea al débil y que se mezcla con la despectiva actitud de unfairness (jugador sucio) que...

... en cierto modo está metida en la ontología del maestro. Quienquiera que sea capaz de recapacitar un instante advierte que él, como maestro, incluso como profesor universitario, tiene la posibilidad desde la cátedra de hacer uso de la palabra para argumentar más extensamente sin que nadie pueda contradecirlo. Con esta situación cuadra, irónicamente, el hecho de que, si alguien da a los estudiantes la oportunidad de que se planteen problemas e intenta aproximar la forma del curso a la de un seminario, en general, no encuentra eco hasta el punto de que los alumnos de los colegios secundarios parecen desear la lección magistral, dogmática (Adorno, 1973a, p. 15).

Ante esto se abre la pregunta por la posibilidad de pedir a un profesor que enseñe con su deseo anulado, como una marioneta presta a dejarse mover por el estudiante; y la respuesta, la mayoría de las veces, es negativa, puesto que el educador es también un sujeto marcado por su deseo. Es más, ese deseo es el que lo lleva a realizar su función, pero, al igual que el estudiante, está limitado por unas normas contextuales y unas demandas implícitas y estereotipadas por parte de sus directores; algo que se reproduce en el ámbito colectivo, en la vida nacional, como una cadena de obediencias, y todas coinciden “... con la disposición a ponerse de parte del poder y a inclinarse exteriormente, como norma, ante el más fuerte, [lo que] constituye la idiosincrasia típica de los torturadores" (Adorno, 1973b, p., 64).

De esta suerte, quedan los estudiantes sometidos a un estad o de permanente necesidad de recibir dictámenes de cualquier tipo, cadena que, en otra esfera, también afecta al docente: esta gobierna su clase, pues este es, al tiempo, gobernado por otras miradas, que controlan su labor.

Ahora bien, a partir de los cuatro puntos anteriores, se apuesta por la idea de que el silencio puede ser concebido como fenómeno semiológico, cuya 
determinación opera como una figura retórica del "malestar docente", correlato de lo que Freud llamó el "malestar en la cultura" (1991b), mal-estar caracterizado por el esfuerzo de una ética confusa:

... en el momento actual los profesores se encuentran con una nueva fuente de malestar al intentar definir qué deben hacer, qué valores van a defender; porque en la actualidad se ha perdido el anterior consenso, al que ha sucedido un proceso de socialización conflictivo y fuertemente divergente; \{es que\} ya no existe el refugio del consenso social. Cualquier actitud del profesor puede ser contestada y habrá fuerzas sociales dispuestas a apoyar la contestación al profesor (Esteve, 1994, p. 30).

Efectivamente, no es dificil certificar el hecho de que el profesor, además de encarnar el código del Prügler; también actúa bajo su rostro de víctima del sistema general, donde ya no es una autoridad, sino un caleidoscopio de roles añadidos al de enseñante; así por caso, debe ser también apóstol, funcionario, operario, nutricionista, abogado, médico, psicólogo, padre provisional, guía espiritual, faro turístico en las salidas pedagógicas y hasta formador de ciudadanía, al tiempo que debe presentarse como intelectual e investigador.

En estas condiciones, la voz del docente se ve forzada continuamente para lograr la atención de sus auditorios y el reconocimiento académico. Pero es de suponer que, tarde o temprano, se cansará de tanto golpe al vacío y de tanta presión; entonces, aparece el silencio, el silencio-signo, el silenciosobreentendido como hecho social que revela el agotamiento de un rol; finalmente, el silencio como una respuesta comunicativa a ese malestar docente, una metonimia pura que encarna la desazón y el desarraigo de ser profesor y que termina como desecho social bajo el diagnóstico clínico del síndrome de burnout, cuyos síntomas más comunes son la angustia y la depresión (Muñoz y Correa, 2014).

\section{Semiótica del poder. El pacto social del silencio}

El quinto y último caso no tiene que ver con el discurrir del silencio, sino con aquel suceso en el cual "el sujeto es silenciado"; esto es, un sujeto o una hermandad política se imputan el derecho de "imponer silencio", de "reducir al silencio" algo o a alguien como estrategia de poder, entendida esta última en términos de control: un grupo es poderoso si controla estratégicamente los conocimientos y los comportamientos de otros grupos a través de la dosificación y manipulación estilística y semántica de los textos públicos, de la limitación de temas y de la imposición de símbolos usados para referir eventos o narrar la(s) historia(s) (Van Dijk, 1999). 
Ahora bien, si el control es la base de todo poder social, entonces ausentar del discurso público ciertos textos y sus saberes resulta una vía regia para mantener el poder e imponer la imagen de un mundo tal y como quiere una enorme minoría que sea percibido por los demás. Este fondo es el objetode-estudio de una "semiótica del poder" que, por su propia naturaleza, daría cuenta de cómo, a través de estrategias retóricas, son fijadas en las mentes de los ciudadanos unas fábulas sobre lo ocurrido en una nación. En suma, es el estudio de cómo se sancionan "ciertos significantes por el sistema oficial de signos", porque “... el sistema oficial bloquea todo el espacio disponible colonizándolo con signos, si no oficiales, por lo menos inofensivos [siendo] uno de los papeles de la propaganda silenciar estrangulando el espacio de los signos disidentes" (Ramírez, 1992, p. 31).

Aprovechando la episteme de esta otra microsemiótica, la del poder, como la otra cara de una semiótica general del silencio, quien es silenciado por efecto de un pacto político es, de suyo, un episodio vivido en el devenir sociohistórico de Colombia, en el cual el poder se ha manifestado a través de la confirmación de hechos modalizados y con argumentos que permiten pensar que lo que se dice y hace es correcto hacerlo tal y como la memoria oficial lo ha presentado. Esto pasó en el Frente Nacional, una coalición bipartidista que excluyó "terceros partidos del poder político" (Bushnell, 2014, p. 318).

Ahora, al revisar las causas sociales para que se llegara a tal coalición absolutista, encontramos que la guerra vivida en Colombia en el siglo XX consistió en una rivalidad entre clases dominantes y clases subalternas (Sánchez, 2007): unas asumiend o el rol ideológico (liberales y conservadores), las otras el rol militar (el campesinado, liberal o conservador). Esta dicotomía en oposición hizo que se situara un nuevo rostro de la violencia y se legitimó la eliminación del adversario por medio del ajusticiamiento privado como solución a los conflictos (Urrego, 2002). Así pues, desde la década de 1940 todos se mataban con todos. Este panorama tóxico fue pan diario de 1946 a 1966 y dejó un saldo de 200.000 muertos; además, la fuerza campesina ganó el deseo de sustituir al poder.

De hecho, el período 1953-1957, el de la dictadura de Rojas Pinilla, actuó como una plataforma de las élites bipartidistas y su destronamiento dio paso al Frente Nacional (1958-1974), que rápidamente impuso un pacto de silencio sobre lo ocurrido. Efectivamente, Lleras Restrepo (presidente de la república entre 1966 y 1970) llamó a que se cancelaran tanto las recriminaciones por el pasado como el enfrentamiento sobre la responsabilidad de lo sucedido con ciertos protagonistas de la violencia, especialmente Laureano Gómez (Schuster, 2010); así que el pacto de silencio fue un silencio generalizado a todo el pueblo. Y este, como cualquier otro pacto, exigió unas estrategias 
de poder social, especialmente el control del texto y del contexto (van Dijk, 1999), que manipuló elementos como qué callar, pero, sobre todo, sobre quién hablar, además de qué y de quién no hablar.

Todo esto se efectuó a través de la prensa nacional (El Espectador, El Tiempo, El Colombiano), regida por un puñado de escritores, rostro moderno de "la ciudad letrada" (Rama, 1984), que no permitió el disenso (Valencia, 2012). En este caso, las estrategias que controlaban el pacto de silencio fueron la naturalización de la violencia, al volverla una entidad suprahistórica sin rostro (Pécaut, 2003), y la imposición de una metonimia con la cual hicieron pasar la dictadura de Rojas Pinilla como un recuerdo encubridor de los culpables; así bloquearon la verdad con una maquinaria oficial de signos, de ausencia de signos, de hecho.

No obstante, y aquí el interés de este ejemplo histórico en el esfuerzo de esbozar una semiótica del silencio (individual y social), este pacto establecido desde arriba por Lleras se rompió desde abajo, y no por la vía del pueblo, sino por la vía de una zona de la cultura letrada. En efecto, pocas semanas antes de que terminara el primer gobierno del Frente Nacional, en 1962, apareció la obra La violencia en Colombia. Estudio de un proceso social (1962, 1980), del sacerdote Germán Guzmán Campos y de los sociólogos Orlando Fals Borda y Eduardo Umaña Luna, quienes hablaron de lo que estaba prohibido hablar y violaron ese implícito que prohibía interpretar ese episodio nacional. Esta rotura de ausencias fue llenada por significantes desmitificadores de la presencia frente al poder social, tales como la culpabilidad igualitaria de los partidos Liberal y Conservador a propósito de La Violencia y el reposicionamiento frente a la aparente victimización del sector del campesinado (Valencia, 2012).

Sobre esto último, Guzmán concluye que el campesino no fue una víctima, sino también un victimario que revivió en el caldo de cultivo de esa guerra una naturaleza arraigada en él para ejercer sevicia por cuenta propia, con independencia de órdenes de sus jefes; en La Violencia, tanto las oligarquías como el pueblo fueron culpables: los primeros no pudieron prever las consecuencias de armar a los campesinos, quienes, ya empoderados, llegaron a extremos inhumanos, una tanatomanía donde aquellos fueron el agente de un sadismo aciago manifestado en la desaparición del otro a través de “... la tortura, la mutilación, la decapitación, la violación y el ultraje del cuerpo de la mujer del bando contrario y la piromanía" (Jiménez, 2013, p. 158). Algo que se evidencia en ya canónicas fotografías que dejan al receptor callado, atónito, con la boca abierta. Así, por ejemplo, la ya emblemática fotografía El cristo campesino, de la colección de Guzmán y que ha sido recuperado en el Informe ¡Basta ya!, del Centro Nacional de Memoria Histórica (GMH, 2013, p. 114); así como también lo vemos, a su vez, 
afinadamente radiografiado en la película La sargento Matacho, del director William González (2015).

\section{A manera de conclusión}

Tanto el docente en el espacio escolar que comunica, justamente por asumir una postura silente, como el sociólogo que rompe un pacto de silencio y muestra que detrás de esto solo hay salvajismo colectivo tienen algo común, a saber: la denuncia que, desde su postura de letrados, saca a la luz un malestar estructural, un "malestar en la cultura", que revela sentidos perdidos para la gran mayoría, pero recuperables como una tensión social autodeterminada por silencios o por su reestructuración como voces de delación.

Lo curioso es que terminan siendo absorbidos por las tramas del lenguaje poderoso y, de rebote, neutralizada su potencia discursiva. Es decir, hay un arrojo de ser disidente frente a los signos del poder, pero al tejer otros signos en unos discursos emergentes, estos se normalizan en su circulación y terminan por no responder ni contradecir. Entonces, queda una especie de "disfagia contrahegemónica", una dificultad de tragar los signos disidentes, por lo que resulta poco funcional la lógica de la resistencia.

En efecto, el docente sigue con una voz sin efectos, mientras que los productos que representan al intelectual quedan en el anaquel como libros más que se citan sin efecto impactante, en un juego bibliográfico roñoso. Al respecto, Žižek (2005) habla de "una suspensión política de la ética", una actitud de denuncia, en suma. No obstante, ¿no será mejor una "compulsión ética de la política", una actitud de silencio que niega todo sacrificio al denunciar? Aquí aparece otro silencio, el que suspende el valor de inter-cambio, y que deja en jaque al sistema. Este es otro tipo de silencio, un "silencio ético" (Barthes, 2004, p. 72), donde hay sentido, mas no antilogía ni réplica; es el silencio del pensamiento, no de la boca; es "el silencio del místico". El filósofo Wittgenstein (1994), en su Tractatus, refiere que lo místico es lo inexpresable (esto ya lo debe estudiar la filosofía y no la semiología).

De esta suerte, confluyen los fines de las microsemióticas aquí esbozadas: la de las ausencias y la del poder, que pueden extenderse a una semiótica general del silencio, a saber: una idea velada sale a la luz, esto es, comunica, ora en el silencio del docente, ora en el tránsito textual del peso letrado; y de esta manera certifica que estamos frente a una sociedad que tropieza con el goce y, así, con el destino oscuro de una ofensiva conquistada por Tánatos, y no por Eros (Brown, 2007), y los matices de víctimas y victimarios son apenas una partición superficial. Aún más, en el sentimiento de unheimliche, que, 
En todo caso, si ha de cimentarse una semiótica diacrónica del silencio, esta debe tener como objeto casi místico el silencio como un texto que solo puede ser leído en un contexto, para, después, dejarnos con la boca abierta; y esto, logrado con un método interdisciplinar, pues finalmente el silencio acude a la intersubjetividad y cómo esta, según la propuesta aquí esbozada, es una talanquera al sentido común: ¿qué es un profesor que no habla?, ¿qué es un intelectual que no es leído y comentado?

\section{Reconocimientos}

Este documento forma parte de la investigación con código 2419167418, adscrita al Centro de Investigaciones y Desarrollo Científico (CIDC) de la Universidad Distrital Francisco José de Caldas.

\section{Referencias}

Abril, C. A. (2008). La pérdida de la voz en los maestros, una lectura desde el psicoanálisis. Revista Desde el Jardín de Freud, (8), 247-261.

Adorno, Th. (1973a). Tabúes relativos a la profesión de enseñar (pp. 12-34). En Consignas. Amorrortu Editores.

Adorno, Th. (1973b). La educación después de Auschwitz (pp. 52-66). En Consignas. Amorrortu Editores.

Barthes, R. (2004). Lo neutro. Notas de cursos y seminarios en el College de France, 1977-

1978. Siglo XXI Editores.

Brown, N. (2007). Eros y Tánatos, el sentido psicoanalítico de la historia. Santa \& Cole.

Bushnell, D. (2014). Colombia. Una nación a pesar de sí misma. Editorial Planeta.

Castilla del Pino, C. (1992). El silencio en el proceso comunicacional (pp. 79-97). En Castilla, del Pino, C. (Comp.). El Silencio. Alianza Editorial.

Cicerón. (2006). Sobre los deberes. Alianza Editorial.

Esteve, J. M. (1994). El malestar del docente. Editorial Paidós.

Esteve, J. M., Franco, S., y Vera, J. (1991). La salud de los profesores. Cuadernos de Pedagogía, (192), 61-67.

Fierro, A. (1992). La conducta del silencio (pp. 47-78). En C. Castilla del Pino (Ed.), El silencio. Alianza Editorial.

Freud, S. (1976 [1893-1895]). Estudios sobre la histeria. En S. Freud, Obras completas (Vol. II) (pp. 23-151). Amorrortu Editores.

Freud, S. (1979a [1905]). El chiste y su relación con el inconsciente. En S. Freud, Obras completas (Vol. VIII) (pp. 9-227). Amorrortu Editores. 
Freud, S. (1979b [1919]). Lo ominoso. En S. Freud, Obras completas (Vol. XVII) (pp. 217-253). Amorrortu Editores.

Freud, S. (1979c [1910]). Un recuerdo infantil de Leonardo Da Vinci. En S. Freud, Obras completas (Vol. XI) (pp. 53-127). Amorrortu Editores.

Freud, S. (1982 [1895]). Proyecto de psicología para neurólogos. En S. Freud, Obras completas (Vol. I) (pp. 323-437). Amorrortu Editores.

Freud, S. (1991a [1926]). Inhibición, síntoma y angustia. En S. Freud, Obras completas (Vol. XX) (pp. 71-165). Amorrortu Editores.

Freud, S. (1991b [1929]). El malestar en la cultura. En S. Freud, Obras completas (Vol. XXI) (pp. 57-140). Amorrortu Editores.

GMH (2013). ¡BASTA YA! Colombia: Memorias de guerra y dignidad. Bogotá: Imprenta Nacional.

González, W. (Director) (2015). La sargento Matacho [Película].

Grice, P. (2005). Lógica y conversación (pp. 41-55). En L. M. Valdés (Ed.), La búsqueda del significado. Editorial Tecnos.

Guzmán Campos, G. (1962). La violencia en Colombia. Estudio de un proceso social (Tomo I). Ediciones Tercer Mundo.

Guzmán Campos, G., Fals Borda, O., y Umaña Luna, E. (1980). La violencia en Colombia. Estudio de un proceso social (Tomo II). Carlos Valencia Editores.

Guzmán, M., Jackson-Menaldi, C., y Rubin, A. (2009). Movimiento paradójico de las cuerdas vocales: un estudio de caso. Revista Chilena de Fonoaudiología, 9(1), 63-78.

Jiménez, A. (2013). El periodo de la violencia en Colombia y el uso de las imágenes del terror, 1948-1965. Revista de Antropología Experimental, 13, 151-165.

Lacan, J. (1967). La lógica del fantasma (1966-1967) [Versión magnética].

Lacan, J. (1987). Los cuatro conceptos fundamentales del psicoanálisis. Editorial Paidós.

Lacan, J. (2001). Las formaciones del inconsciente. Seminario, libro V (1957-1958). Editorial Paidós.

Lemoine, E. (1982). El grito: el sueño del cosmonauta. Editorial Paidós.

Melman, C. (1984). Nouvelles Etudes sur L'hystérie. Clims-Denöel.

Muñoz, C. y Correa, C. (2014). El papel del docente reflexivo como estrategia del síndrome de Burnout en relación con las prácticas educativas. Revista Hallazgos, 11(22), 385-401.

Ortiz, C. (1994). Historiografía de la violencia (pp. 371-423). En B. Tovar (Comp.), La historia al final del milenio. Editorial UN.

Pécaut, D. (2003). Violencia y política en Colombia. Elementos de reflexión. Hombre Nuevo Editores.

Rama, Á. (1984). La ciudad letrada. Editorial Hanover.

Ramírez, J. (1992). El significado del silencio y el silencio del significado (pp. 15-45). En C. Castilla del Pino (Ed.), El silencio. Alianza Editorial.

Rodríguez, R. (2011). Des-bordes de una escritura que no resultaría de una precipitación del significante [PDF] [Ponencia]. IV Jornadas de Carteles Encrucijadas de la Clínica, Escuela Freudiana de Buenos Aires, Argentina. http://www.efbaires.com.ar/files/texts/ TextoOnline_440.pdf 


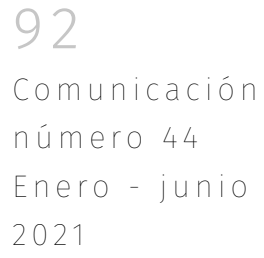

Sánchez, G. (2007). Los estudios sobre la violencia: balance y perspectivas (pp. 17-32). En G. Sánchez y R. Peñaranda (Comps.), Pasado y presente de la violencia en Colombia. La Carreta Editores.

Schuster, S. (2010). Colombia: ¿país sin memoria? Pasado y presente de una guerra sin nombre. Revista de Estudios Colombianos, 36, 30-38.

Thomas, M.-C. (1999). Las formas del silencio en el olvido de Signorelli (pp. 79-89). En J. D. Nasio (Ed.), El silencio en psicoanálisis. Amorrortu Editores.

Urrego, M. A. (2002). Intelectuales, Estado y nación en Colombia: de la guerra de los Mil Días a la Constitución de 1991. Siglo del Hombre Editores.

Valencia, A. (2012). La Violencia en Colombia de M. Guzmán, O. Fals y E. Umaña y las trasgresiones al Frente Nacional. Revista Colombiana de Sociología, 35(2), 15-33. Van Dijk, T. A. (1999). El análisis crítico del discurso. Revista Anthropos, (186), 23-35. Wittgenstein, L. (1994). Tratactus Lógico Philosophicus. Ediciones Altaya. Žižek, S. (2005). La suspensión política de la ética. Fondo de Cultura Económica. 